\title{
MENINGKATKAN KEMAMPUAN BERPIKIR LOGIS ANAK USIA DINI MELALUI METODE BERNYANYI PADA ANAK KELOMPOK B
}

\author{
Dewiana Permatasari $^{1}$, Euis Eti Rohaeti ${ }^{2}$, Sharina Munggaraning Westhisi ${ }^{3}$ \\ ${ }^{1}$ Institut Keguruan dan Ilmu Pendidikan (IKIP) Siliwangi, Cimahi. \\ ${ }^{2}$ Institut Keguruan dan Ilmu Pendidikan (IKIP) Siliwangi, Cimahi. \\ ${ }^{3}$ Institut Keguruan dan Ilmu Pendidikan (IKIP) Siliwangi, Cimahi. \\ 1.
}

\begin{abstract}
One aspect of cognitive development that can be developed by early childhood is the ability to think logically in children, for that we need a learning method that can improve the ability of logical thinking in children, one of which is through the method of singing. Through singing methods, children's logical thinking ability will increase. By singing and moving according to the song lyrics, the child will imagine and the child's logical thinking ability will improve properly. This research is a quantitative study with a quasi-experimental design involving children in the B age group which is made into two classes, namely the experimental class and the control class. Based on the results of the study, the data obtained is that the average value of the experimental class gain is 2.05 while the average value of the control class gain is 0.44 , which means that after being given treatment, namely the method of learning singing in the experimental class, the ability of children to think logically is increased compared to the control class that was not given treatment. Therefore, the method of singing can be used as an alternative learning method to improve the ability to think logically early childhood.
\end{abstract}

Keywords: Logically Thinking Ability, Singing Method

\begin{abstract}
ABSTRAK
Salah satu aspek perkembangan kognitif yang dapat dikembangkan oleh anak usia dini adalah kemampuan berpikir logis pada anak, untuk itu diperlukan suatu metode pembelajaran yang dapat meningkatkan kemampuan berpikir logis pada anak, salah satunya adalah melalui metode bernyanyi. Melalui metode bernyanyi, kemampuan berpikir logis anak akan meningkat. Dengan bernyanyi serta melakukan gerakan sesuai lirik lagu yang dinyanyikan, maka anak akan berimajinasi dan kemampuan berpikir logis anak akan meningkat dengan baik. Penelitian ini menggunakan metode kuasi eksperimen dengan desain penelitian control group desain dengan menggunakan dua kelas yang terdiri dari B1 kelas eksperimen dan B2 kelas kontrol di RA Multazam. Berdasarkan hasil penelitian, data yang diperoleh adalah bahwa rata-rata nilai gain kelas eksperimen 2,05 sedangkan rata-rata nilai gain kelas kontrol yaitu 0,44 yang artinya bahwa setelah diberikan treatment bernyanyi di kelas eskperimen, kememapuan berpikir logis pada anak meningkat dibandingkan dengan kelas kontrol yang tidak diberikan treatment. Maka dari itu, penelitian ini direkomendasikan kepada para pendidik anak usia dini, untuk menerapkan metode bernyanyi kepada anak agar perkembangan berpikir logis anak dapat meningkat.
\end{abstract}

Kata Kunci: Kemampuan Berpikir Logis, Metode bernyanyi 


\section{PENDAHULUAN}

Pendidikan merupakan salah satu upaya untuk mengembangkan dan meningkatkan sumber daya manusia yang berkualitas, seperti halnya dikemukakan oleh Naisbitt (dalam Tilaar, 2002: 116) "Education and training must be a major priority; they are the keys to maintaining competitiveness". Berdasarkan penelitian yang telah dilakukan oleh Putra (2007: 15), bahwa salah satu upaya yang dapat dilakukan untuk meningkatkan sumber daya manusia adalah meningkatkan kualitas pendidikan yang berfokus kepada pengembangan kemampuan berpikir siswa. Sementara itu, pemikiran kritis, kreatif, sistematis, dan logis dapat dikembangkan melalui pendidikan matematika. Hal ini sangat memungkinkan karena matematika memiliki struktur dengan keterkaitan yang kuat dan jelas satu dengan yang lainnya serta berpola pikir yang konsisten (Depdiknas, 2003).

Pendidikan anak usia dini (PAUD) adalah jenjang pendidikan sebelum jenjang pendidikan dasar atau sekolah dasar (SD) yang merupakan suatu upaya pembinaan yang ditujukan bagi anak sejak lahir sampai dengan usia enam tahun yang dilakukan melalui pemberian rangsangan pendidikan untuk membantu pertumbuhan dan perkembangan jasmani dan rohani anak, agar anak memiliki kesiapan dalam memasuki pendidikan lebih lanjut, yang diselenggarakan pada jalur formal, nonformal, dan informal. Kegiatan bernyayi adalah salah satu kegiatan yang menyenangkan bagi anak, dan pengalaman bernyanyi ini memberikan kepuasan tersendiri kepada anak. Kegiatan bernyanyi juga merupakan alat bagi anak untuk mengungkapkan pikiran dan perasaanya. Metode pembelajaran bernyanyi merupakan metode pembelajaran yang menggunakan unsur seni yang digemari oleh anak usia dini. Metode pembelajaran bernyanyi bukanlah termasuk metode pembelajaran yang baru bagi pembelajaran anak usia dini, melainkan metode pembelajaran lama hanya masih sedikit guru yang menggunakan metode pembelajaran bernyanyi dalam kegiatan pembelajarannya. Kegiatan pembelajaran bernyanyi pada anak usia dini merupakan kegiatan yang harus ada di setiap kegiatan pembelajaran yang wajib dilakukan setiap hari. Hasil penelitian Suryaningsih (2015: 132) menyatakan bahwa metode bernyanyi berperan besar terhadap perkembangan bahasa anak, karena dalam proses bernyanyi secara tidak langsung melibatkan indera pendengaran untuk mendengarkan, mulut untuk bernyanyi dan berbicara serta menghafalkan kata. Sehingga secara tidak langsung dengan kegiatan bernyanyi, kemampuan bahasa anak dapat meningkat.

Hasil dari pemaparan di atas, menunjukkan bahwa metode bernyanyi dapat meningkatkan kemampuan berpikir logis anak. Sayangnya, masih jarang ditemukan penggunaan metode pembelajaran bernyanyi yang dapat memengaruhi kemampuan berpikir logis AUD, sehingga peneliti ingin mengetahui pengaruh metode bernyanyi terhadap kemampuan berpikir logis anak usia dini khususnya pada anak kelompok B.

\section{METODOLOGI}

Sugiyono, (2012: 2) bahwa Metode penelitian pada dasarnya merupakan cara ilmiah untuk mendapatkan data dengan tujuan dan kegunaan tertentu. Cara ilmiah berarti kegiatan penelitian itu harus didasarkan dengan ciri-ciri keilmuan yaitu rasional, empiris dan 
sistematis. Metode yang gunakan adalah metode kuasi eksperimen dengan menggunakan desain, kelompok kontrol nonequivalent eksperimen. Pada kuasi eksperimen ini subjek tidak di kelompokan secara acak, tetapi penelitian menerima keadaan subjek seadanya.
A : O
$\mathrm{X}$
$\mathrm{O}$
$\mathrm{A}: \mathrm{O}$
$\mathrm{O}$

\section{Keterangan:}

$\mathrm{A}=\quad$ Sampel yang dipilih berdasarkan kelas

$\mathrm{O}=$ Pretest dan postest (Tes kemampuan pengenalan warna)

$\mathrm{X}=$ Perlakuan pembelajaran dengan metode eksperimen.

Metode kuasi ekperimen mempunyai kelompok kontrol, tetapi tidak dapat berfungsi sepenuhnya untuk mengontrol variabel-variabel luar yang mempengaruhi pelaksanaan ekperimental. (Sugiyono, 2008). Variabel terikat dalam penelitian ini adalah kemampuan berpikir logis pada anak, sedangkan variabel bebas dalam penelitian adalah metode pembelajaran bernyanyi. Subjek penelitian ini adalah anak kelompok B dengan rentang usia 56 tahun di RA Multazam. Kelompok B RA Multazam sebagai kelas eksperimen yang akan menerima treatment (perlakuan) yaitu metode bernyanyi dengan jumlah anak sebanyak 27 anak dan kelompok kedua masih di sekolah yang sama yaitu kelompok B dengan jumlah anak sebanyak 24 anak sebagai kelas kontrol yang menggunakan metode konvesional. Instrument penelitian ini menggunakan hasil dari spss versi 20 dengan penilaian pretest Uji $\mathrm{T}$, dan, posttest Uji $\mathrm{T}$.

\section{HASIL DAN PEMBAHASAN}

\section{HASIL}

Pada penelitian ini, teknik analisis statistik yang akan digunakan adalah uji normalitas dan uji homogenitas. Berdasarkan perhitungan kolmogorovsmirnov, nilai Sig data pre-test pada kelas eksperimen menunjukkan hasil yang signifikan 0,200 karena 0,200> $\alpha$ $(0,05)$ maka berdistribusi normal dan sedangkan pada data pre test kelas kontrol menunjukkan 0,121 karena 0,121 $>\alpha(0,05)$ maka hasil pre test kelas kontrol berdistribusi normal.

Tabel 1

Hasil Uji Normalitas, Data Pre Test

Kelas Eksperimen dan Kelas Kontrol

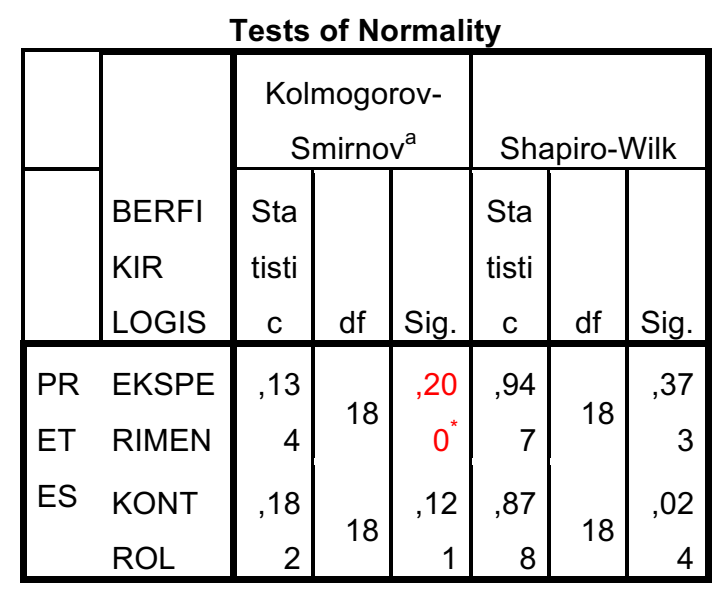

*. This is a lower bound of the true significance.

a. Lilliefors Significance Correction

Pada hasil homogenitas data pre test kelas eskperimen dan kelas kontrol 0,912 karena $0,912>\alpha(0,05)$ maka data tersebut bervarian homogen.

Tabel 2

Hasil Uji Homogenitas

Data Pre Test

Kelas Eksperimen dan Kelas Kontrol

Test of Homogeneity of Variance 


\section{JURNAL GERIA}

ISSN : 2614-6347 (Print) 2714-4107 (Online)

Vol.2 | No.6 | Septemeber 2019

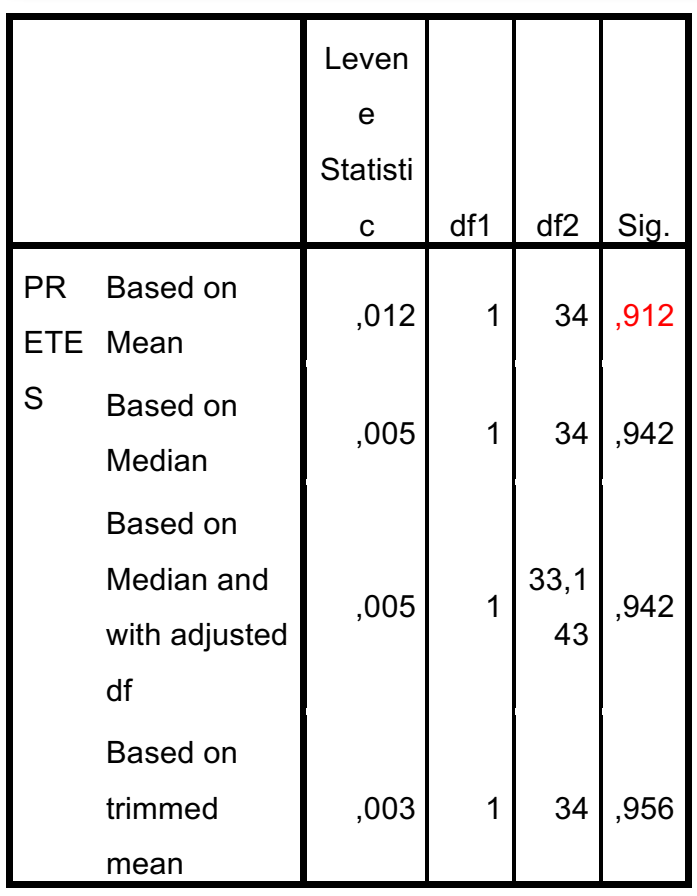

Dari hasil uji signifikansi diatas maka diperoleh hasil bahwa nilai Sig. 0,912 . Karena $0,912>0,05$ maka Ho diterima. Dengan demikian hasil pretest kelas ekperimen dan kelas kontrol tidak terdapat perbedaan yang signifikan baik secara keseluruhan maupun pada setiap aspeknya. Hal ini berarti bahwa pada saat pretest (sebelum perlakuan) tingkat kecerdasan berpikir logis anak antara kelas ekperimen dan kelas kontrol tidak ada perbedaan.

Data postes pada kelas eksperimen menunjukkan hasil yang signifikan 0,233 karena $0,233>\alpha(0,05)$ maka berdistribusi normal dan sedangkan pada data post test kelas kontrol menunjukkan 0,073 karena $0,073>\alpha(0,05)$ maka hasil post test kelas kontrol berdistribusi normal.
Tabel 3

Hasil Uji Normalitas, Data Post Test

Kelas Eksperimen dan Kelas Kontrol

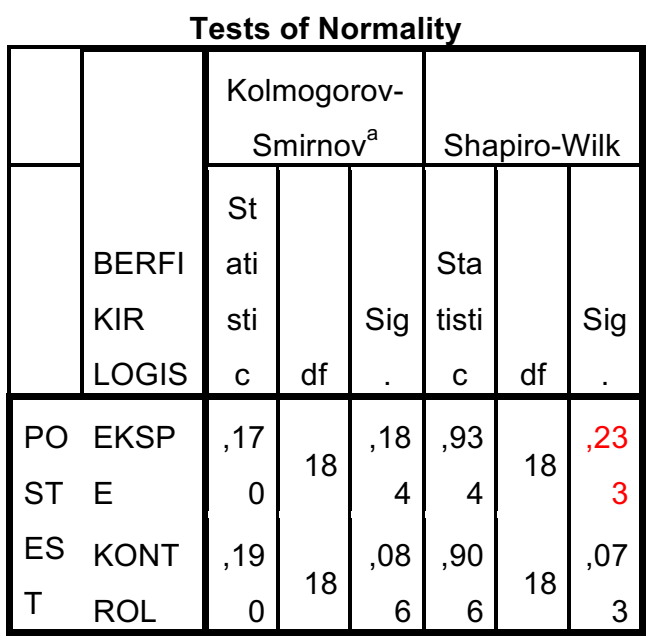

Pada hasil homogenitas data posttes kelas eskperimen dan kelas kontrol 0,912 karena 0,912> $>(0,05)$ maka data tersebut bervarian homogen. Hasil penelitian uji normalitas dan homogenitas diperoleh bahwa data berdistribusi normal dan homogen.

Tabel 4

Hasil Uji Homogenitas

Data Post Test

Kelas Eksperimen dan Kelas Kontrol

Test of Homogeneity of Variance

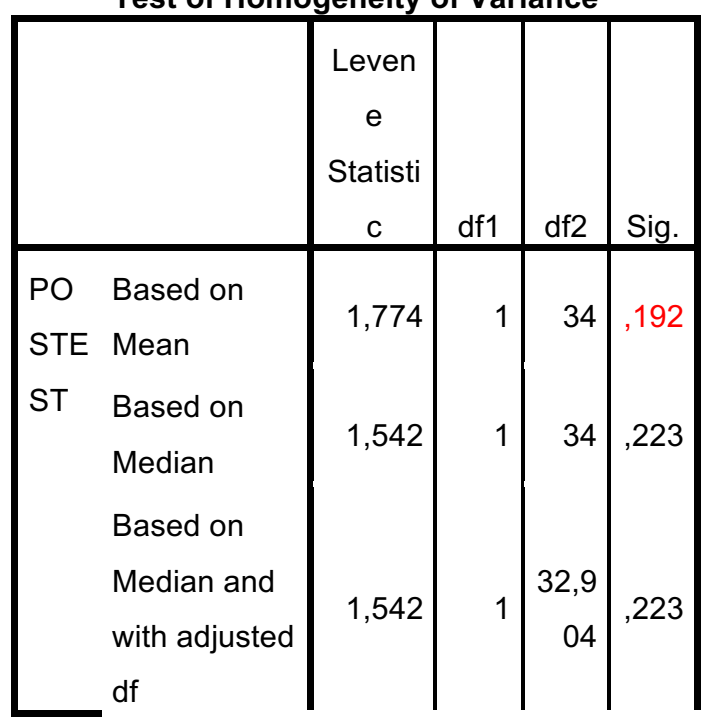




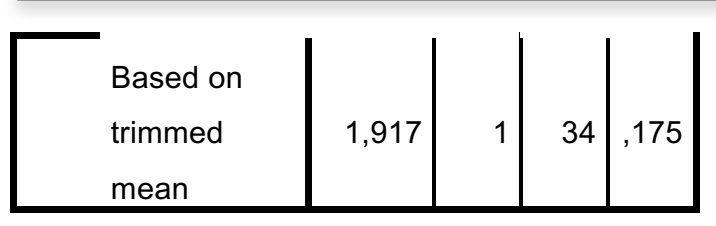

Hasil penelitian uji normalitas dan homogenitas diperoleh bahwa data berdistribusi normal dan homogen. Maka dari itu analisis data selanjutnya menggunakan uji t independen.

Tabel 5

Hasil Uji t Independen, Data Post Test Kelas Eksperimen dan Kelas Kontrol

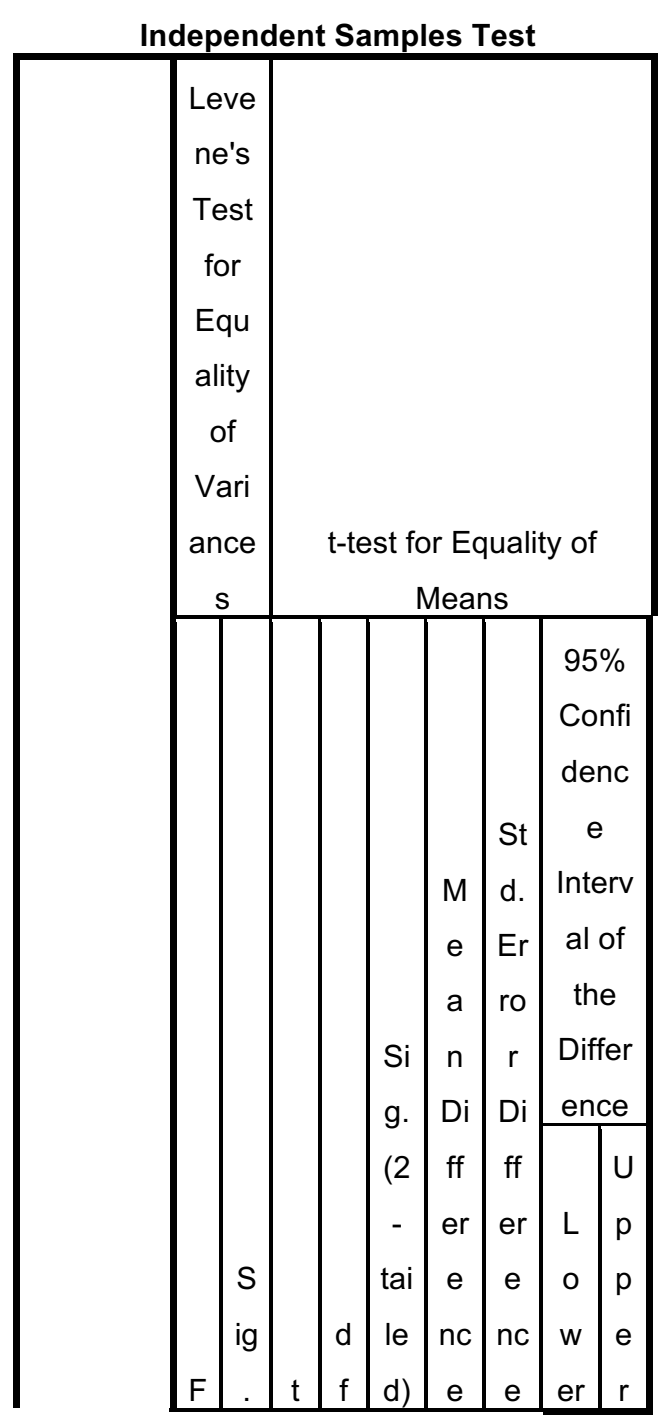

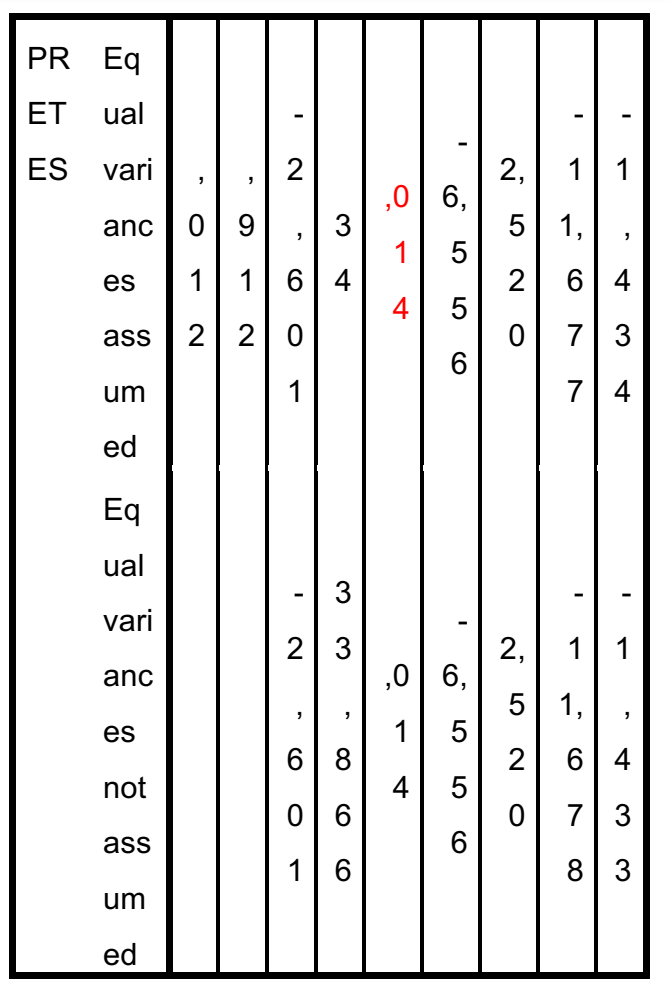

Tabel 7

Hasil Uji t Independen, Data Post Test Kelas Eksperimen dan Kelas Kontrol

Independent Samples Test

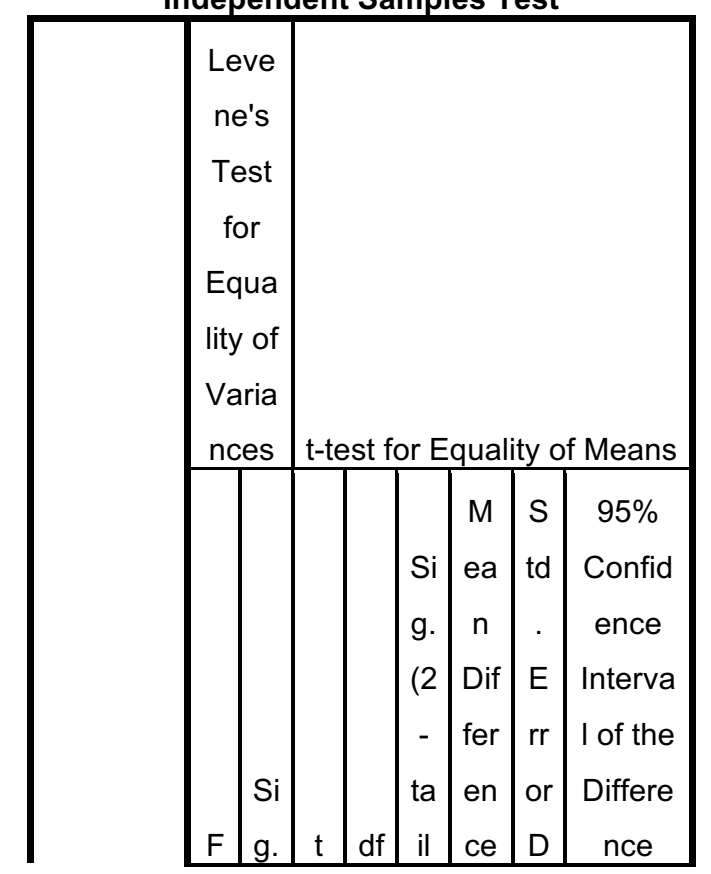




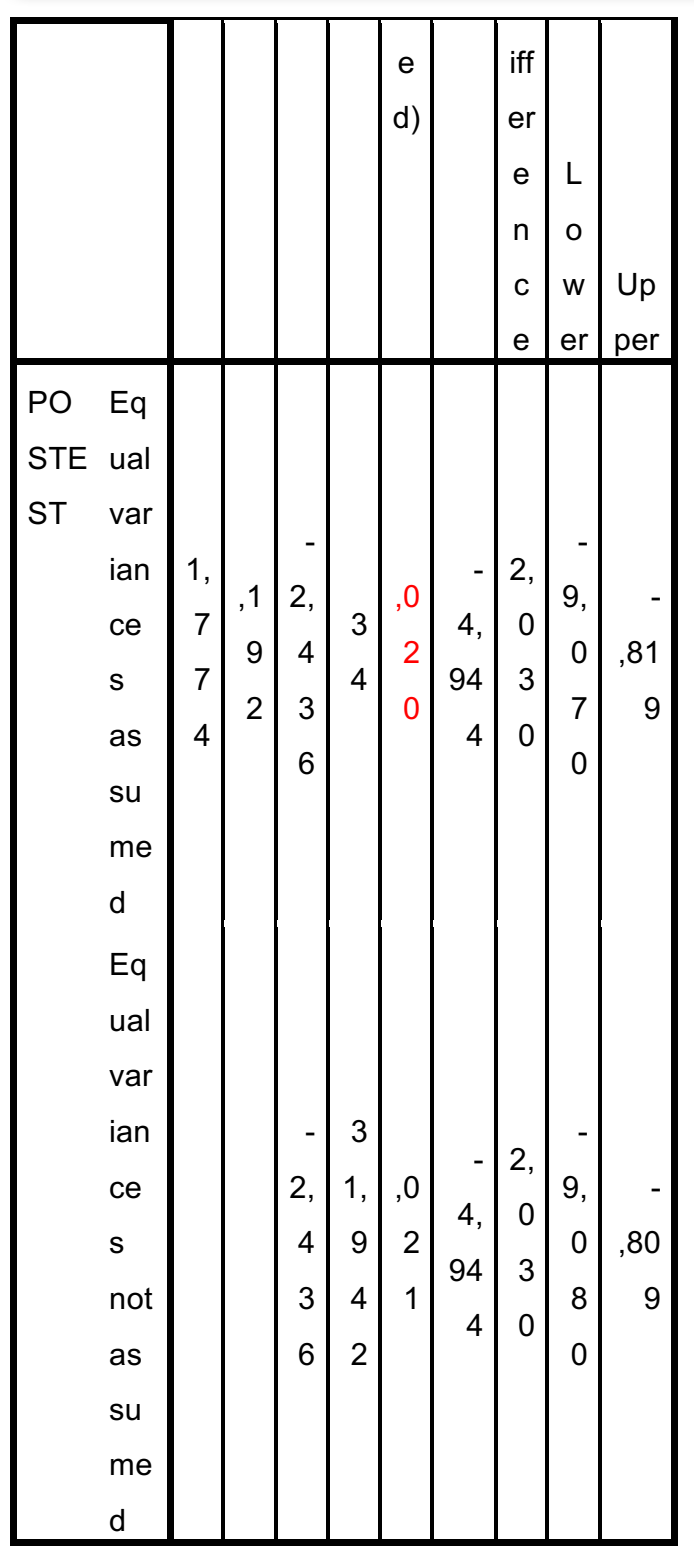

Berdasarkan hasil data pretest dan posttest antara kelas esksperimen dan kelas kontrol didapatkan hasil gain. Hasil gain diperoleh dari jumlah data posttest dikurang data pretest. Melalui hasil gain data pretest dan posttest diperoleh nilai rata-rata gain, untuk nilai rata-rata gain kelas eskperimen adalah 2,055 sedangkan nilai rata-rata gain kelas kontrol adalah 0,444 . Hal ini menunjukkan bahwa metode pembelajaran bernyanyi memiliki pengaruh yang baik terhadap peningkatan kemampuan berpikir logis anak. Lebih rinci lagi dapat dilihat pada tabel berikut ini:

Tabel 6

Peningkatan Kemampuan Berpikir

Logis Anak Kelas Kontrol dan Kelas

Eksperimen Sebelum dan Sesudah

Menggunakan Metode Bernyanyi

\begin{tabular}{|l|l|l|}
\hline Kelas & $\begin{array}{l}\text { Jumlah } \\
\text { Gain }\end{array}$ & $\begin{array}{l}\text { Rata-rata } \\
\text { Gain }\end{array}$ \\
\hline $\begin{array}{l}\text { Kelas } \\
\text { Kontrol }\end{array}$ & 8 & 0,444444 \\
\hline $\begin{array}{l}\text { Kelas } \\
\text { Eksperimen }\end{array}$ & 37 & 2,055556 \\
\hline
\end{tabular}

Pada awalnya perolehan data pretest kemampuan berpikir logis anak pada kelas kontrol dan eksperimen setelah dilakukan perhitungan uji normalitas dan uji homogenitas menunjukkan bahwa kedua kelas tersebut berdistribusi normal dari populasi yang homogen. Ini menunjukkan bahwa anak pada kelas kontrol dan kelas eksperimen memiliki karakter kemampuan berpikir logis yang tidak jauh berbeda atau sama dan setelah dibuktikan dengan hasil uji t independen sampel menunjukkan nilai Sig lebih besar dari $p$-value $(0,912>0,05)$. Hal ini menunjukkan bahwa tidak terdapat perbedaan pada perkembangan berpikir logis anak diantara kedua kelas terbeut. Hal ini disebabkan karena pada kelas eskperimen belum dilakukan perlakuan sehingga berpikir logis anak pada kedua kelas tersebut tidak jauh berbeda. Hal ini dapat terlihat ketika melakukan kegiatan menggunakan metode bernyanyi, anak akan dapat berpikir lebih logis mengenai banyak hal melalui nyanyian dan gerakan.

\section{Pembahasan}

Berdasarkan hasil penelitian, terdapat perbedaan antara kemampuan berpikir logis pada anak di kelas eksperimen setelah diberikan perlakuan. Hal tersebut 
dikarenakan metode pembelajaran bernyanyi membantu daya pikir anak untuk berpikir lebih logis lagi. Pada kelas eksperimen di RA Multazam sebelum menggunakan metode bernyanyi, pada saat kegiatan pembelajaran untuk mengembangkan daya pikir pada anak, guru-guru di sana menerapkan pembelajaran biasa (pemberian tugas) seperti mewarnai. Melalui pembelajaran biasa yang diterapkan oleh guru di sana, anak-anak dibiasakan untuk melakukan pekerjaan dan menyelesaikan tugasnya sendiri tanpa ada contoh seperti nyanyian atau gerakan terlebih dahulu. Untuk sebagian anak yang gaya belajarnya audio visual akan kesulitan dalam mengerjakannya. Tetapi untuk anak yang gaya belajarnya tidak audio visual, akan dengan mudah menyelesaikannya.

Pemilihan metode pembelajaran yang tepat sangat membantu perkembangan anak. Salah satunya adalah metode pembelajaran bernyanyi yang dapat meningkatkan kemampuan berpikir logis pada anak. Melalu nyanyian dan gerakan yang dilakukan oleh anak, maka daya pikir anak akan lebih meningkat dan akan lebih logis lagi dalam berpikir.

Dari yang awalnya anak hanya mengetahui bunga dari gambar saja (mewarnai), mereka jadi tahu bentuk bunga yang sesungguhnya sebelum mereka melihat bentuk bunga yang asli, melalui nyanyian dan gerakan beserta dengan gambar nyata.

Metode pembelajaran bernyanyi dapat meningkatkan kemampuan berpikir logis pada anak usia 5-6 tahun (TK B).

\section{KESIMPULAN}

Berdasarkan rumusan masalah yang menyatakan bahwa di dalam dunia pendidikan anak usia dini, metode pembelajaran bernyanyi yang diterapkan untuk meningkatkan kemampuan berpikir logis anak usia dini kelompok B lebih baik dari pada metode pembelajaran biasa. Kemampuan berpikir logis yang muncul adalah anak mampu mengelompokkan benda berdasarkan warna dan ukuran sambil bernyanyi, anak juga mampu mengurutkan beda dari yang paling besar ke paling kecil begitunjuga sebaliknya.

Implementasi pembelajaran dengan menggunakan metode pembelajaran bernyanyi sudah terlaksana dengan baik sesuai dengan rencana yang sudah dirancang peneliti, dimana anak usia dini terlihat lebih mengerti dengan pembelajaran. Pembelajaran menajdi lebih menyenangkan dan anak-anak antusias dengan gerakan dan musik.

\section{DAFTAR PUSTAKA}

Departemen Pendidikan Nasional. (2003).

Kurikulum Standar Kompetensi Matematika SD dan MI. Jakarta: Depdiknas.

Naisbitt, J., Naisbitt, N., \& Philips, D., (2002: 116). High Tech High Touch, Pencarian Makna di Tengah Perkembangan Pesat Teknologi, Terjemahan Dian R Basuki, Bandung: Mzam Media Utama.

Putra . (2007: 15). Pendidikan Matematika Realistik Indonesia (PMRI)

Suryaningsih. (2015). Pengaruh Metode bernyanyi Terhadap Perkembangan Bahasa Anak Usia Dini Di Lembaga PAUD Melatill Madiun Tahun Ajaran 2015-2016.21 November 2015.

Sugiyono. (2012: 2). Metode Penelitian Kuantitatif dan Kualitatif $R \& D$. Bandung CV. Alfabeta. 